\title{
COMBINING DISTANCE AND FACE-TO-FACE TEACHING AND LEARNING IN SPATIAL COMPUTATIONS
}

\author{
Elizabeth-Kate Gulland, A G T Schut and Bert Veenendaal \\ Department of Spatial Sciences, Curtin University, Kent St Bentley 6102, Western Australia \\ (e.gulland, t.schut, b.veenendaal)@curtin.edu.au
}

Commission VI, WG VI/1,2

KEY WORDS: gis, higher education, geographic information science, student engagement, e-learning, distance learning, programming, problem solving

\begin{abstract}
:
Retention and passing rates as well as student engagement in computer programming and problem solving units are a major concern in tertiary spatial science courses. A number of initiatives were implemented to improve this. A pilot study reviews the changes made to the teaching and learning environment, including the addition of new resources and modifications to assessments, and investigates their effectiveness. In particular, the study focuses on the differences between students studying in traditional, oncampus mode and distance, e-learning mode. Student results and retention rates from 2009-2011, data from in-lecture clicker response units and two anonymous surveys collected in 2011 were analysed. Early results indicate that grades improved for engaged students but pass rates or grades of the struggling cohort of students did not improve significantly.
\end{abstract}

\section{INTRODUCTION}

The Department of Spatial Sciences at Curtin University caters for a wide range of students. These disparate student groups, including undergraduate and postgraduate; on-campus and distance learners; and surveying and geographic information science (GISc) courses, necessitate a range of different teaching and learning approaches, often within a single unit of study.

This paper is a case study of the Spatial Computations ( $\mathrm{SpC})$ unit which embodies this challenging combination of factors. It is a unit of study designed to introduce students in the spatial sciences to spatial problem solving and computer programming. It is a compulsory unit in all spatial sciences courses run by the department.

Historically there has been a poor retention and pass rate of students in this unit, particularly for on-campus undergraduate students. Student engagement varies widely depending on the student's course and learning mode.

A number of different techniques have been applied to the unit to improve student outcomes and retention in groups that have traditionally struggled with the unit. The use of online learning resources are foundational to the techniques being used for such diverse cohorts of students. The key to successful learning is how to provide the three L's - lectures, laboratories, libraries in a blended online/on-campus environment so as to actively engage students in their learning (Veenendaal 2000).

\subsection{Aims}

The purpose of this project is to investigate the effectiveness of measures taken in the Spatial Computations unit over the period 2009-2011 on student learning, retention, pass rates and attitudes towards the subject material and the learning activities.

\section{BACKGROUND}

\subsection{Student Groups}

The $\mathrm{SpC}$ unit is mandatory for the undergraduate Bachelor of Science degrees in Geographic Information Science and Mine \& Engineering Surveying, and the Bachelor of Surveying degree. It is also required in the postgraduate Graduate Diploma and Graduate Certificate programs GISc and the Master of Science (Geospatial Science) course of study.

As well as students studying in traditional on-campus mode, $\mathrm{SpC}$ has a large number of students studying in distance mode which is conducted fully online. Most of the distance students are postgraduates whereas most of the undergraduates are studying in traditional face-to-face mode (Table 1).

\begin{tabular}{|l|c|c|}
\hline Course of Study (2011) & $\begin{array}{c}\text { On-campus } \\
\text { students }\end{array}$ & $\begin{array}{c}\text { Distance } \\
\text { students }\end{array}$ \\
\hline Surveying or Mine Surveying (65) & $94 \%$ & $6 \%$ \\
GISc undergraduate (18) & $18 \%$ & $6 \%$ \\
GISc postgraduate (39) & $36 \%$ & $64 \%$ \\
Other postgraduate (3) & $67 \%$ & $33 \%$ \\
\hline
\end{tabular}

Table 1. Proportion of on-campus and distance students commencing $\mathrm{SpC}$ unit

2.1.1 Student Attitudes: As a general rule, students of GISc courses are more receptive than those of Surveying to the idea of computer programming as it is directly applicable to GISc tasks such as spatial analysis and online map design.

Surveying students tend to be more resistant to the idea of learning computer code. This is particularly the case with undergraduate students, whose view of surveying centres more around outdoor fieldwork and operating its associated equipment. 
Although a major aim of the $\mathrm{SpC}$ unit is to develop problemsolving skills, students are primarily concentrating on the implementation, i.e. the programming component. In general, $\mathrm{SpC}$ students lack a proper comprehension of the importance of analysing the problem at hand. Consequently, the link between problem solving skills and the implementation of a solution in computer code has been difficult to convey to them.

The difficult learning curve for programming and problemsolving education is not new to this unit although very few studies are found in the literature addressing this problem. Hawi (2010) found that the two most common factors identified by students as contributing to failure of a programming unit were a poor learning strategy (relying on memorisation rather than understanding) and lack of study.

\section{DELIVERY OF CONTENT}

The $\mathrm{SpC}$ unit is delivered using both face-to-face teaching and via ilectures (Preston, Phillips et al. 2010) that stream the automatically recorded audio and visuals of each lecture. In terms of peer and instructor interaction, on-campus students rely on face-to-face engagement and distance students primarily use the online discussion forums open to all students. This concords with other research on the use of ilectures and online forums (von Konsky et al 2009; Kehrwald 2008).

To address the issues of poor performance and engagement in the $\mathrm{SpC}$ unit, a number of techniques were applied to the lecture and practical session activities of the unit.

\subsection{Practical Work Activities}

For a practical unit such as $\mathrm{SpC}$, it is essential for students to develop skills and gain hands-on experience through practical exercises. Different techniques were applied to monitor students' practical work, provide feedback to them and encourage them to participate in the practical exercises.

In 2009, students had to submit worksheets from six practical sessions. These were then marked and returned to students in order to provide feedback to them. This approach required a large time commitment from tutors and, as a result, feedback often reached students later than desired.

3.1.1 Quiz and Assignment Assessments: In 2010, a different approach towards assessments was taken based on findings by Veenendaal (2001) that online quizzes were an appropriate tool for formative assessment. The submission of practical worksheets were replaced with four open-book online quizzes which included questions taken directly from the practical sessions. At the same time, the on-paper mid-semester test was removed from the unit, shifting the focus from summative assessment to formative assessments.

In the same year, the practical assignment, as a summative assessment, was revised to run in parallel with practical sessions. The practicals were rewritten so that students developed methods and algorithms for specific tasks that could be re-used or contribute directly towards their assignment tasks. The aim was to encourage the students to work through all the practicals as each weekly solution would contribute in some way towards the assignment. It was also intended as an inducement for students to commence work earlier on the assignment.
3.1.2 Practical Checks: In 2011, to supplement the formative online quiz assessments, a practical check was introduced. Given that the development of programming skills is an outcome of the unit, there was a need to both ensure that students were progressing in the development of these skills, and to give them feedback in regards to their progress. The practical check required students to demonstrate a small task to their tutor who could assess their skill capabilities and provide them with feedback. Modified checks were applied to distance students, where each had to submit a screen capture of their task.

Three separate checks were designed to assess different skills at appropriate points in the learning process:

- Debugging and documenting code (week 3)

- $\quad$ Calling procedures in code (week 6)

- Writing procedures in code (week 8)

\subsection{Lecture Features}

A number of features were added to the on-campus lectures to assist students in becoming further engaged with the study materials. This assisted both on-campus students who attended the lectures and distance students who could work through the ilectures in which the student engagement was recorded..

The features added were the introduction of interactive clicker units and a role-playing game. A third feature was an open question and answer session to encourage students to ask questions and receive answers and further explanations about any areas that they needed help with. Although the participation of students present was high, overall attendance was low.

3.2.1 Clicker Response Units: To encourage two-way interaction in on-campus lectures, personal response units (clickers) were introduced to $\mathrm{SpC}$ for the first time in 2011. Each student holding a clicker can answer a multiple choice question displayed on a lecture slide, and the responses are instantly collated and displayed in chart form on the next slide (Kay \& LeSage 2009).

The aim was to engage students more in on-campus lectures and build a dialogue between lecturer and students. The anonymous nature of clicker responses encourages a higher rate of involvement and more honest answers (Burke da Silva, K et al 2007). The clickers were used to engage students in recalling the material of the previous lecture, focus their minds on concepts of the upcoming topic, and obtain feedback from them regarding their progress and reflection on their own learning.

3.2.2 Variable Game: In the third on-campus lecture, a game was introduced to involve students more directly in a basic programming concept - using variables. Students were assigned roles within a program and then sealed instructions were given to the first student to start an interaction between students acting as 'variables' and those acting as 'processes'.

This is an example of the type of interaction that can be applied to the on-campus group of students. Although the distance students can view the interaction via the ilectures, it is the oncampus undergraduate students that are primarily targeted with this activity as they are most at risk for resisting learning of some of the basic concepts (see Section 2.1). 


\section{METHODOLOGY}

Data on student grades and retention for the years 2009-2011 were collected and statistically analysed for each student cohort. Additionally, student feedback was received through multiple means and at different points within their learning process.

Feedback was obtained from students in relation to workload, feedback from teachers, difficulty of the material, and perceived relevance of the material and resources. Two tools were used to gather these responses: clicker response units used during oncampus lectures, and two online surveys that were disseminated to both on-campus and distance students.

As well as collecting data, questions were added to both these tools to help improve student engagement and to raise awareness of available resources within the unit.

Finally, formal unit evaluations involving online eVALUate surveys, which are standard for all units that students undertake, were used to receive responses from students near the end of their study period.

\subsection{Questions for Clicker Response Units}

During 10 of the 12 on-campus lectures, students were asked to respond to questions relating to the content and their attitudes towards it. Clickers were used to collect information about the student groups attending the lecture, such as course of study.

Between three and five question slides were used in each lecture. Each slide posed a multiple-choice question to which students responded using their clicker devices. Questions were designed to gather various types of information. Examples included:

- $\quad$ Finding out background of students - "What is your level of experience with computers?"

- Determining the status of students; whether or not they were keeping up with the pace and workload "Last week's tutorial was... (easy, challenging, difficult, ...)" "Have you completed tutorial 8?"

- Discovering students' use of resources and their perceived usefulness - "Quiz feedback was ... (not checked yet, helpful, confusing, ...)"

- Testing knowledge obtained through previous lectures and/or practical sessions - "What is the advantage of polymorphism?"

- $\quad$ Finding problem areas within the material - "Arrays (now clear, unclear, not yet confident...)"

- Applying skills - "This loop iterates... (0 times, 1 time, 5 times, ...)"

- Discovering attitudes - "In my opinion, flowcharts are (...essential, useful, nuisance, a mystery, ...)

These questions were not designed solely for collecting student data. An important aim was to use the questions to involve students much more in the material, to encourage them to work through practical problems, and to raise students' awareness of gaps in their knowledge.

\subsection{Surveys}

All students across Curtin University are encouraged to participate in the online eVALUate survey for each of their units. This survey seeks student opinions on areas such as the clarity of unit outcomes, relevance of assessments and workload. It also asks students to reflect on their own motivation and enthusiasm for the unit.

In 2011, students were also asked to submit responses to two anonymous, online surveys which were tailored to measure student attitudes to items including perceived importance and understanding of the content, workload, and use of resources.

Each survey was open to student submissions for one week. The first opened in week four, immediately after the first online assessed quiz and in the week after the lecture containing the variable game (Section 3.2.2). The second survey opened in week 12 , the second last teaching week.

Most of the survey questions were the same across both surveys to enable comparison of any shift in attitude of the students. In addition, a small number of questions were added to each survey that were specific to the activities of the unit at the time of the survey's release:

- Survey A asked about attitudes to the on-campus variable game.

- Survey B asked additional questions relating to assignments, feedback from graders, peer interaction and external tutoring.

\section{PRELIMINARY RESULTS}

Some distance students were, at times, in geographic proximity to the Curtin campus, and could occasionally attend on-campus lectures and/or practicals. This may have affected the perceived differences between distance and on-campus students.

\subsection{Clicker Response Units}

There was positive feedback from students for the use of clickers in on-campus lectures. Qualitative survey responses from the students showed that they found the clicker response system helpful. For instance: "I think the use of clickers is great as it gives instant feedback to how well the student understand a certain part of the lecture".

\subsection{Variable Game}

In-lecture clicker responses in the week following the variable game showed that nearly half of the students who participated in the game still found the concept of variables very abstract.

Responses from students to the first online survey (which was opened the week after the variable game lecture) showed that $89 \%$ of on-campus students attended the lecture with the variable game and, of those, $58 \%$ found it somewhat useful and $3 \%$ found it very useful. The remaining $39 \%$ did not find it useful. This appears to indicate that not all students actively engaged in the activity, and as a result, continued to struggle with the concept of "variables".

\subsection{Student Attitudes}

A high proportion of undergraduate students - particularly surveying students - were resistant to the idea of learning computer programming.

In the first lecture of 2011, on-campus students were asked via clicker devices why they were studying the SpC unit. They 
could choose only one option. Of the students attending the lecture, nearly $40 \%$ chose the response "It's compulsory but I don't see the point" (Figure 1). A total of $65 \%$ of students attending this lecture were in a surveying or mine and engineering surveying undergraduate course.

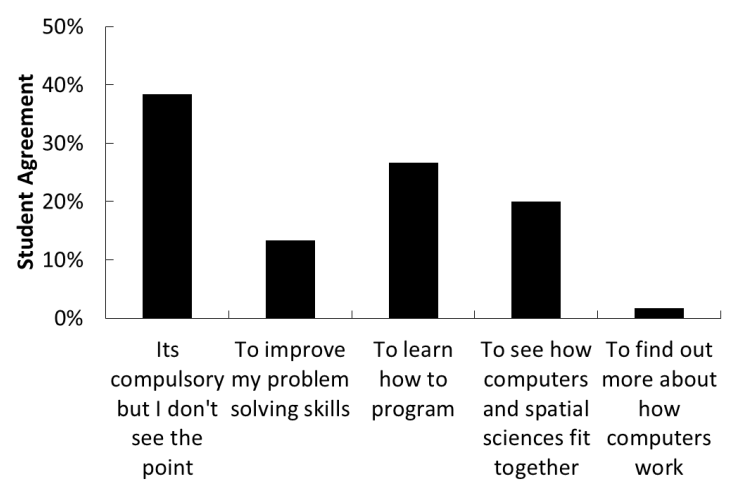

Figure 1. Students' reasons for studying $\mathrm{SpC}$

The final eVALUate student surveys confirmed that undergraduate students (most of whom study surveying courses) have a negative disposition towards computer programming. On average over $2009-2011$, only $42 \%$ of undergraduates agreed with the statement "I am motivated to achieve the learning outcomes in this unit" compared to $71 \%$ of postgraduate students.

\subsection{Student Retention and Pass Rates}

In general the student retention was poor, with retention rates of $77 \%, 71 \%$ and $70 \%$ over $2009-2011$ across all student groups.

Of those students still enrolled at the end of the semester, approximately $80 \%$ sat the final exam over the years 2009 to 2011. The pass rates, calculated on the basis of enrolled students who completed all assessments, are shown in Figure 2. It identifies a drop in the pass rate after 2009, however the final exam assessments in that year were inflated due to a less stringent marking scheme. For 2011, there was a small improvement in the pass rate from 2009. Whether or not this is due to the teaching and learning initiatives implemented will need further investigation. The aim is to improve both pass and retention rates.

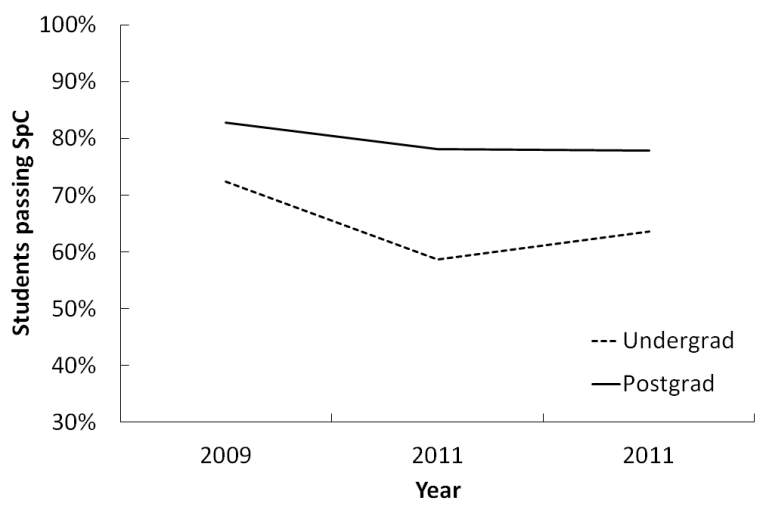

Figure 2. Proportion of undergraduates and postgraduates completing all assessments that passed $\mathrm{SpC}$
5.4.1 Attendance: The attendance rate at on-campus lectures tends to drop gradually over the semester. This is partly due to drop-out of students but also to loss of interest and increasing workloads with assignment work across all units. As an indication, the number of on-campus responses in 2011 using the clickers dropped from 60 in week 1 to 20 in week 11 (the $10^{\text {th }}$ lecture of 12 ).

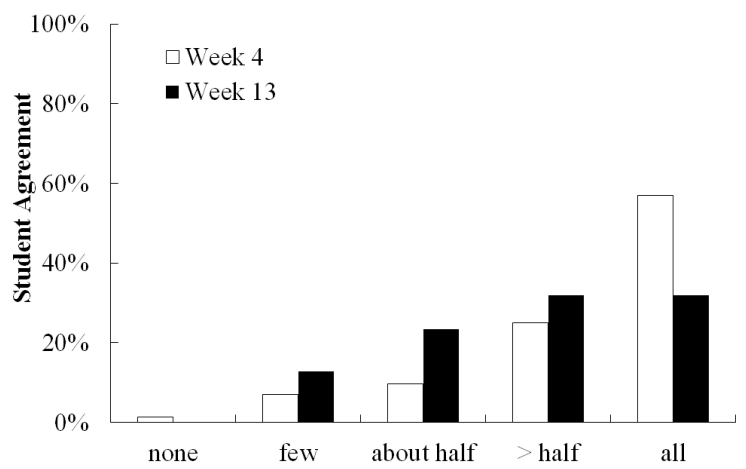

Figure 3. Comparison of the frequency of surveyed lecture attendance of on-campus students

Over a similar period, attendance at on-campus practicals dropped by approximately half; across three of the practical lab sessions, there were 41 attendees in the first week and 18 in week 12 .

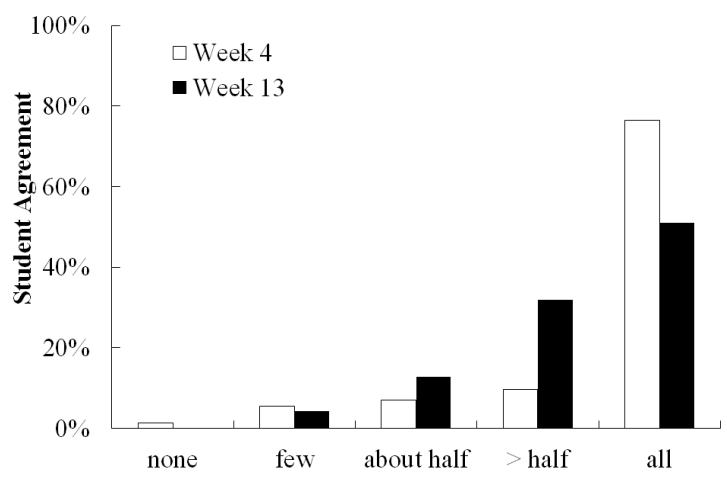

Figure 4. Comparison of the frequency of surveyed practical attendance of on-campus students

The attendance rate was higher for practical sessions than for lectures. This is not unexpected, and is a reflection of how students respond to more interactive sessions. Also, students were aware that lecture recordings could be accessed outside the actual lecture sessions.

5.4.2 Practical Work Activities On-campus students were more likely (56\% in final survey) than distance students $(22 \%)$ to view the practical checks as incentives for putting more effort into practical exercises. This can be partially attributed to the higher levels of motivation amongst distance students.

A total of $42 \%$ of on-campus students did not perceive the practical checks as useful to them, and a further $40 \%$ only found them moderately useful. It can be conjectured that students were unaware of the link between more effort in practical exercises and a deeper understanding of the skills and concepts being taught. 
Due to the workload for tutors in supporting student learning during practical exercises whilst simultaneously running practical checks, the third check was only run for a minority of students.

The integration of practical work with assignment tasks was designed to reduce the workload of students. However, survey results showed that the majority of students found linking the solutions they developed for specific practical tasks and their assignment work confusing. As a result, they struggled to make sense of how to apply the solution to a new problem such as their assignment. This highlights the need to further develop their problem solving skills and ability to identify solvable components of a complex problem.

5.4.3 Pass rates: Figure 2 identifies a drop in the pass rate after 2009, however the final exam assessments in that year were inflated due to a less stringent marking scheme. Anecdotally, SpC students who passed the unit in 2009 had similar or greater difficulties with programming and problemsolving skills in later units than 2010 or 2011 students.

\subsection{Student Grades}

Results in all versions of the unit showed two distinct groups of marks. Figure 5 shows the distribution for undergraduate and postgraduate students with postgraduate students tending to perform better than undergraduate students. This has been the case historically for this unit. The overall shape of the grades distribution did not change with the new features implemented in 2011 .

However, the range in grades was slightly larger with marks for high-achieving students, both undergraduate and postgraduate, higher than in previous years. From this, it appears that the engaged students profited most from the additional resources supplied. The distribution of the grades was still bi-modal, which can be attributed to the undergraduate (mostly oncampus) and postgraduate (mostly distance) student cohorts.

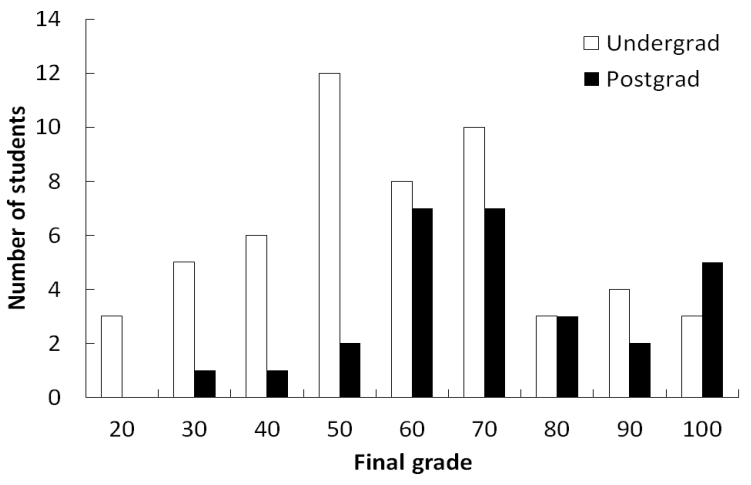

Figure 5. 2011 results: undergraduate (open) and postgraduate (filled)

\section{CONCLUSIONS}

The additional online learning resources and on-campus activities implemented to further engage students did not affect the attendance rates or the grades of the target group significantly. However, it did appear to influence the grades of the higher achievers - the average grade of the top students rose in 2011. From this it can be concluded that the extra resources were of most benefit to students who were already motivated and engaged. Whilst this is a positive outcome, it is disappointing that the target group of low achievers did not show a more significant increase in retention or final result grades.

Some of the new initiatives, such as practical checks and the variable game, were difficult to implement for distance students, and others such as the clickers have a limited influence in further engaging distance students. More resources are needed in order to develop parallel engaging resources for these students.

Given the disparate outcomes for the largely on-campus undergraduate students and the largely distance postgraduate students, the priority in future developments would be to target resources and activities to further engage undergraduate and oncampus students, and taking into consideration the differences between the diverse student cohorts.

\subsection{Enhancing Content}

The amount of content and subsequent workload was seen by students as a significant challenge, with $81 \%$ of on-campus and $87 \%$ of distance students recording in the final teaching week that they found 'the volume of materials to absorb' a challenge in the unit. This can, to a large extent, be attributed to the wide range of topics and insufficient amount of time spend on each in the unit.

The pace of the unit as dictated by the volume of material gave students insufficient time to grasp essential concepts and apply them in developing their skills. This $\mathrm{SpC}$ unit requires dedication and focus of the students to master the concepts and practical skills. Undergraduate students in particular lack the necessary engagement in their learning for this unit.

As a result, future offerings of the $\mathrm{SpC}$ unit will reduce the amount of content so as to make the unit more manageable. This will also give more time to engage students in particular topics, and provide more time for students to understand and apply the knowledge and skills.

A wide variation in student attitude and engagement exists between the student cohorts. In particular, the surveying students had a negative attitude towards developing programming skills and didn't sufficiently engage in the activities and opportunities presented to them. Further efforts need to be applied to engage this group more directly in appreciating and understanding the value of learning problem solving and programming concepts and skills. In other words, strategies to link together the available resources, and the process of how students engage with these resources, needs to be pursued. This could include some knowledge construction principles identified for computer programming by Kordaki (2010) as emphasising algorithmic logic, performing meaningful and contextually relevant learning activities, reflection of the programming experience and dynamic visualisation of complex concepts and procedures.

\subsection{Enhancing Practices}

The practical checks appeared to have a positive effect on the motivation of on-campus students. However, their implementation in class was limited by time constraints on tutors. Additional tutor resources need to be applied for the next 
delivery of the unit. To be more inclusive of distance students, consideration may need to be given to developing some online resource to assist in monitoring the practical checks and to assist the distance tutors with their one-to-one interaction with these students.

Additionally, further consideration must be given to pedagogical techniques that ensure students not only achieve the outcomes, but have an understanding of the outcomes. This may include a shift in emphasis from syntax and code to problem-solving and logic. This would involve further research into understanding the learning process in how students arrive at a solution to a problem at a higher abstract level before translating that into a code and syntax level. This also corresponds to some of the recommendations of Hawi (2010).

\subsection{Enhancing Learning Activities and Resources}

6.3.1 Clicker Response Units in Lectures: As found by Grimm et al (2007), the positive student response to the use of clickers does not necessarily translate to a significant improvement in final grades. However, the positive responses received from students in the $\mathrm{SpC}$ unit show that clickers are indeed a useful tool for increasing the engagement of students, improving student attitudes towards the learning in the unit and providing a further means of student feedback throughout the duration of the unit, rather than only at selective instances or at the end of the unit via set student surveys.

Given the positive response from students, the use of clicker response units in lectures will be continued in the $\mathrm{SpC}$ unit. Consideration will be given to additional means by which the use of the clickers can further engage students and extract feedback for both the students and the instructor.

More time needs to be spent on integrating the responses with the lecture material so that there is more flexibility to concentrate on areas that students highlight in lectures as problematic.

6.3.2 Variable Game: the overall student response to the hands-on variable game was positive (see Section 5.2). There were many students attending the lecture who did not find the game useful and it appeared not to contribute to a better understanding of the concept of "variables". However, there was a sufficiently large proportion of on-campus students who found this interactive exercise beneficial, to warrant the continuation of this game exercise in the unit

More time needs to be spent on designing other tasks to involve the on-campus students in the concepts and skills that they struggle with. Any new tasks or resources need to target the undergraduate students at the lower end of the grades scale, who appear to be unmotivated and disengaged, and hence do not have incentives to build up their problem-solving and programming knowledge and skills.

6.3.3 Catering for Different Needs: This study clearly highlighted vast differences in attitude and results between student cohorts. It is anticipated that changes to the content and delivery will need to be applied in order to address the different requirements for learning computer programming and problem solving between undergraduate and postgraduate students as well as between the different cohorts of undergraduate students including surveying and GISc students.

\section{REFERENCES}

Burke, da Silva K, D Wood, and R I Menz. 2007. Are the benefits of clickers due to the enforcement of good pedagogy? Higher Education Research and Development Society of Australasia (HERDSA), 8-11 Jul 2007, Flinders University, Adelaide, South Australia.

Grimm, P. E., E. Soares, J. Agrawal, and S. Law. 2007. Technology facilitated class participation in a principles of marketing course. ANZMAC 2007: reputation responsibility, relevance, Dunedin, New Zealand.

Hawi, N. 2010. Causal attributions of success and failure made by undergraduate students in an introductory-level computer programming course. Computers \& Education, 54, pp. 11271136.

Kay, R.H. and A. LeSage 2009. A strategic assessment of audience response systems used in higher education. Australasian Journal of Educational Technology, 25(2), pp. 235-249. www.ascilite.org.au/ajet/ajet25/kay.html (accessed 5 Sep. 2011)

Kehrwald, B. 2008. Towards community-based learner support: a case study. ASCILITE 2008 Melbourne: hello! where are you in the landscape of educational technology?, 30 Nov - 3 Dec 2008, Melbourne, Australia

Kordaki, M. 2010. A drawing and multi-representational computer environment for beginners' learning or programming using C: Design and pilot formative evaluation. Computers \& Education, 54, pp. 69-87.

Preston, G., R. Phillips, M. Gosper, M. McNeill, K. Woo, and D. Green 2010. Web-based lecture technologies: highlighting the changing nature of teaching and learning. Australasian Journal of Educational Technology, 26(6), pp. 717-728.

Veenendaal, B. 2000. Flexible and web-based delivery of GIScience in higher education. Proceedings of the International IT Conference on Geo-Spatial Education, Hong Kong, 6-8 July.

Veenendaal, B. 2001. Flexible assessment in GIScience education. In A. Herrmann and M. M. Kulski (Eds), Expanding Horizons in Teaching and Learning. Proceedings of the 10th Annual Teaching Learning Forum, 7-9 February 2001. Perth, Western Australia. http://lsn.curtin.edu.au/tlf/tlf2001/ veenendaal.html (accessed 5 Sep. 2011)

von Konsky, B. R, J. Ivins, and S. J Gribble. 2009. Lecture attendance and web based lecture technologies : a comparison of student perceptions and usage patterns. Australasian Journal of Educational Technology, 25(4), pp. 581-595.

\section{ACKNOWLEDGEMENTS}

The authors would like to thank the tutors and students of Spatial Computations 181 and 581 over the period 2009-2011 who provided their feedback and suggestions towards the continuing process of enhancing this unit. Also, the support and funding for this project contributed by the Department of Spatial Sciences at Curtin University is gratefully acknowledged. 